\title{
Rekürren over kanseri hastalarında uygulanan tersiyer ve kuaterner sitoredüksiyon cerrahilerinin sağ kalıma etkisi ve morbiditesi
}

\author{
Analysis of survival and morbidity outcomes after tertiary and quaternary \\ cytoreductive surgeries in recurrent ovarian cancer patients \\ Seda Yüksel Şimşek ${ }^{1}$ Hüseyin Akıllı ${ }^{2}$ İrem Alyazıcı Küçükyıldız ${ }^{3}$ Ali Ayhan ${ }^{2}$ (D) \\ ${ }^{1}$ Başkent Üniversitesi Tıp Fakültesi Adana Dr. Turgut Noyan Hastanesi Kadın Hastalıkları ve Doğum \\ Bölümü, Adana, Türkiye \\ ${ }^{2}$ Başkent Üniversitesi Tıp Fakültesi Ankara Hastanesi Kadın Hastalıkları ve Doğum Bölümü, Ankara, Türkiye \\ ${ }^{3}$ Cumhuriyet Üniversitesi Tıp Fakültesi Hastanesi Kadın Hastalıkları ve Doğum Bölümü, Sivas, Türkiye
}

\section{ÖZ}

Amaç: Rekürren over kanseri hastalarında uygulanan tersiyer ve kuaterner sitoredüktif cerrahilerin sağ kalım ve morbidite sonuçlarının incelenmesidir.

Gereç ve Yöntem: Hasta kayıtları retrospektif olarak incelenmiştir. Sağ kalım oranlarının tespitinde Kaplan-Meier sağ kalım analizi ve karşılaştırmalar için log-rank testleri kullanılmıştır. Tüm analizlerde anlamlı istatistiki değer $\mathrm{p}:<0,05$ olarak kabul edilmiştir.

Bulgular: Çalışmaya Şubat 2007-2012 tarihleri arasında rekürren over kanseri tanısı ile takip edilen 106 hasta dahil edildi. İkinci rekürrens nedeniyle 47 hastaya tersiyer, 3. rekürrens nedeniyle 12 hastaya kuaterner sitoredüksiyon uygulandı. Ortalama tanı yaşı $54,1 \pm 11,2$; ortanca takip süresi 40 ay idi. Ortalama ve ortanca sağ kalım süreleri sırasıyla $66,5 \pm 5,1$ ve 56 ay idi. İkinci rekürrens sonrası tersiyer sitoredüksiyon yapılan hastaların sağ kalımı, yalnızca kemoterapi verilen hastalardan anlamlı olarak uzundu $(73,8 \pm 7,3$ vs $52,0 \pm 5,6$ ay) (p:0,039). Tersiyer sitoredüksiyon hastalarında, platin duyarlı olanların sağ kalım süresi dirençli olanlardan daha uzun olarak tespit edildi $(78,8 \pm 8,2$ vs $44,4 \pm 6,4$ ay) (p:0,121). Üçüncü rekürrens sonrası kuaterner sitoredüksiyon yapılan ve yapılmayan hastaların sağ kalım sürelerinin ise benzer olduğu görüldü $(63,7 \pm 7,5 ; 62,7 \pm 8,3$ ay) (p:0,616). Tersiyer ve kuaterner sitoredüksiyonlarda intraoperatif komplikasyon oranı \%15; postoperatif komplikasyon oranı ise \%20-25 idi. Cerrahi sonrası yoğun bakım intiyacı; tersiyer ve kuaterner sitoredüksiyonlar sonrası primer ve sekonder sitoredüksiyonlardan daha fazla idi $(p:<0,0001)$.

Sonuç: Rekürren over kanseri hastalarında, tersiyer sitoredüksiyonun sağ kalım üzerine olumlu etkisi olabilir. Tersiyer ve kuaterner sitoredüksiyon cerrahileri sonrasında yoğun bakım intiyacının primer ve sekonder sitoredüktif cerrahilerden daha fazla olması; bu geniş cerrahilerin deneyimli merkezlerde gerçekleştirilmesini zorunlu kılmaktadır.

Anahtar Sözcükler: Rekürren over kanseri, tersiyer sitoredüksiyon, kuaterner sitoredüksiyon.

\section{ABSTRACT}

Aim: To analyze the outcomes of tertiary and quaternary cytoreduction surgeries in recurrent ovarian cancer patients.

Materials and Methods: Patients' data were obtained retrospectively from hospital database. Kaplan-Meier method has been used to analyze survival outcomes.

Sorumlu yazar: Seda Yüksel Şimşek

Başkent Üniversitesi Tıp Fakültesi Adana Dr. Turgut Noyan

Hastanesi Kadın Hastalıkları ve Doğum Bölümü, Adana, Türkiye

E-posta: dryukselseda@hotmail.com

Başvuru tarihi: 12.05.2020 Kabul tarihi: 19.10.2020 
Results: $A$ hundred and six patients diagnosed with recurrent ovarian cancer between dates February 2007-February 2012 were included into study. Tertiary and quaternary cytoreduction surgeries have been performed in 47 and 15 patients, respectively. Mean age at diagnosis was $54.1 \pm 11.2$ years. Median follow up time was 40 months (min.: 4; max.: 130 months). Overall and median survival times were 66.5 \pm 5.1 and 56 months, respectively. Overall survival of patients operated for tertiary cytoreduction was significantly longer than survival of patients who had second recurrence but not

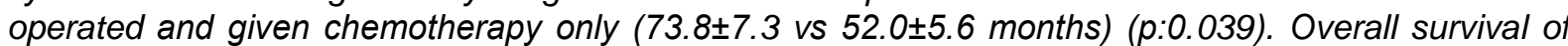
platin-sensitive group was longer than platin-resistant group among tertiary cytoreduction group

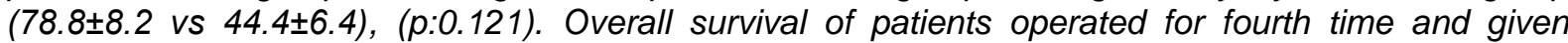
chemotherapy only were $63.7 \pm 7.5 ; 62.7 \pm 8.3$ months respectively (p:0.616). Intraoperative complication rate is around $15 \%$ for both tertiary and quaternary cytoreduction. Postoperative complication rate is around $20-25 \%$. The rate of intensive care unit requirement was highest after third and fourth cytoreductive surgeries compared to first and second cytoreduction and this difference was statistically significant ( $p:<0.0001)$.

Conclusion: Tertiary cytoreduction may have benefit on survival outcomes for recurrent ovarian cancer patients. Postoperative intensive care unit requirement is higher in tertiary and quaternary cytoreduction compared to primary and secondary cytoreduction surgeries.

Keywords: Recurrent ovarian cancer, tertiary cytoreduction, quaternary cytoreduction.

\section{GíRiş}

Epitelyal over kanseri, jinekolojik kanserler arasında en ölümcül olanıdır. Geçmişten günümüze hastalığın patogenezi, önlenmesi, erken teşhisi gibi konularda birçok çalışma yapılmıştır. Epitelyal over kanseri hastalarının primer tedavisinde optimal sitoredüktif cerrahinin en önemli basamak olduğu birçok çalışmada gösterilmiştir (1-5). Optimal sitoredüktif cerrahi sonrasında ise, platin bazlı kemoterapi uygulamaları over kanserinin standart tedavi modalitesini oluşturmaktadır. Optimal sitoredüksiyon ve sonrasında verilen platin bazlı kemoterapi rejimleri ile \%80-90 oranında remisyon elde edilebilmesine rağmen \%70-90 hastada rekürrens izlenmektedir (6).

Rekürren epitelyal over kanseri hastalarının tedavisinde sitoredüktif cerrahinin sağ kalımı uzatacağı yönünde görüş bildiren çalışmalar literatürde mevcuttur (7-10). Hastalıksız sağ kalımı (disease free survival-DFS) daha uzun olan, optimal sitoredüksiyonun sağlanarak geride rezidü tümör bırakılmayan ve rekürrenslerin tek anatomik alan ile sınırlı olan hastalarda, sekonder sitoredüktif cerrahinin sağ kalıma pozitif etkisinin daha belirgin olduğu ortaya konulmuştur $(9,11,12)$. Bickell ve ark.'nın çalışmasında; rekürren vakalarda, cerrahi ve kemoterapi kombinasyonunun yalnızca kemoterapiye sağ kalım anlamında üstün olduğu sonucuna ulaşılmıştır (13). Jinekolojik onkoloji grubunun (GOG-213) randomize prospektif çalışmasında ise platin duyarlı rekürren hasta grubunda cerrahi ve adjuvan kemoterapi kombinasyonunun yalnızca kemoterapiye, sağ kalım açısından üstünlüğü olmadığı sonucuna ulaşılmıştır (14).
İkinci ve üçüncü rekürrenslerde, sitoredüktif cerrahinin etkisi de retrospektif çalışmalar ve vaka serilerinde değerlendirilmiştir (15-20). Bu çalışmalarda, genel olarak tersiyer ve kuaterner sitoredüksiyon operasyonlarının sağ kalıma olumlu etkisinin olduğu sonucuna ulaşılmıştır. Bu olumlu etkinin özellikle optimal sitoredüksiyonun mümkün olduğu, cerrahi sonrası geride minimal tümör yükünün kaldığı ve tedavisiz intervali (TFI) uzun olan hastalarda daha belirgin olduğu görüşü belirtilmektedir. Genel olarak kabul edilen görüş sekonder, tersiyer ve kuaterner sitoredüksiyon operasyonlarının sağ kalıma katkı sağlayacağı yönündedir. $\mathrm{Bu}$ sonuçların çoğu retrospektif çalışmalar tarafından ortaya konulmuştur ve güncel prospektif çalışmaların sonuçları bu görüşler ile çelişkili görünmektedir. Halen hangi hasta grubunun bu geniş cerrahi operasyonlardan en çok faydayı sağlayacağı konusunda açık bir fikir birliği bulunmamaktadır. $\mathrm{Bu}$ retrospektif gözlemsel çalışmanın amacı da rekürren over kanseri hastalarına uygulanan tersiyer ve kuaterner sitoredüktif cerrahilerin sağkalım sonuçları ve morbiditelerini ortaya koyarak literatüre katkı sağlamaktır.

\section{GEREÇ VE YÖNTEM}

Çalışmaya merkezimizde Şubat 2007-Şubat 2012 tarihleri arasında takip ve tedavileri gerçekleştirilen, primer tanıları epitelyal over karsinomu olan ve sekonder, tersiyer, kuaterner sitoredüktif cerrahileri yapılan hastalar dahil edilmiştir. Hastaların medikal tedavi ve cerrahi kararları merkezin tümör konseyi ile kararlaştırılmıştır. Çalışmaya dahil edilen hastaların primer sitoredüktif cerrahisi dış 
merkezde yapılmış olanların verilerine operasyon notları, patoloji raporları, epikrizlerinden ve gerekli hallerde hastalar telefon ile aranarak ulaşılmıştır. Cerrahileri merkezimizde gerçekleştirilenlerin verilerine ise hastanenin veri tabanından ulaşılmıştır. Çalışma için merkezin 'Tıp ve Sağlık Bilimleri Araştırma Kurulu'ndan KA $12 / 03$ proje numarası ile etik kurul onayı alınmıştır. Evreleme, Uluslararası Jinekoloji ve Obstetri Federasyonu (FIGO) sistemi kullanılarak yapılmıştır. Optimal sitoredüksiyon, intraoperatif izlemde operasyon sonunda gözle görülür tümör bırakılmaması olarak tanımlanmıştır. Her operasyon öncesi hastalar anestezistler tarafından değerlendirilmiş ve hasta ve yakınından operasyon risklerini detaylı anlatan aydınlatıımış onamları alınmıştır. Hastalıksız dönem, primer cerrahi sonrası verilen kemoterapi rejiminin bitiş tarihinden itibaren klinik, laboratuvar ya da radyolojik olarak tespit edilen rekürren hastalık tanısına kadar geçen süre olarak tanımlanmıştır. Platin bazlı kemoterapi rejiminin bitiminden altı aydan daha kısa süre içerisinde rekürren hastalığı olanlar platin dirençli hastalık olarak tanımlanırken; altı aydan daha uzun sürede rekürrensi olanlar platin duyarlı olarak sınıflandırılmıştır. Rekürren hastalık tanısı rutin kontroller sırasında uygulanan klinik muayene, radyolojik görüntüleme; pozitron emisyon tomografi (PET-BT), bilgisayarlı tomografi (BT), manyetik rezonans görüntüleme (MR), ultrasonografi (USG) ve karsinoembryonik antijen 125 (CA-125) düzeyleri göz önüne alınarak konulmuştur. İntraoperatif komplikasyonlar; operasyon sırasında gerçekleşen organ yaralanma ve perforasyonları, kanama ve hematom oluşumu olarak tanımlanmıştır. Postoperatif komplikasyonlar ise hastanın postoperatif ilk 30 günlük dönemde yaşadığı komplikasyonları içermektedir. Sadece oral medikasyonlarla ya da yatak başı girişimle tedavi edilebilen komplikasyonlar derece 1 ; intravenöz tedavi, kan transfüzyonu ya da total parenteral beslenme gerektirecek komplikasyonlar derece 2; girişimsel radyoloji, terapötik endoskopik girişim, angiografik girişim ya da entübasyon gerektiren komplikasyonlar derece 3; majör rehabilitasyon ve organ rezeksiyonuna yol açan komplikasyonlar derece 4 ve hastanın ölümüne yol açan komplikasyonlar derece 5 komplikasyon olarak sınıflandırılmıştır.

\section{İstatistiksel Analiz}

Çalışmaya dahil edilen hastalardan elde edilen veriler SPSS 17.0 istatistik programına aktarılarak analiz edilmiştir. Sabit değişkenlerin değerlendirilmesinde ortalama değerler ve standart sapma değerleri kullanılmıştır. Kategorik değişkenlerin değerlendirilmesinde rakamsal değerler ve yüzde değerler kullanılmıştır. Kategorik değişkenlerin karşılaştırılmasında Kikare testi yönteminden yararlanılmıştır. Sağ kalım oranlarının tespitinde Kaplan-Meier sağ kalım analizi ve karşılaştırmalar için log-rank testleri kullanılmıştır. Tüm analizlerde anlamlı istatistiki değer $\mathrm{p}:<0,05$ olarak kabul edilmiştir.

\section{BULGULAR}

Çalışmaya merkezimizde Şubat 2007-Şubat 2012 tarihleri arasında rekürren epitelyal over kanseri nedeniyle tedavi edilmiş 106 hasta dahil edildi. Yüz altı hastanın tümüne sekonder sitoredüktif cerrahi uygulanırken, 2. kez rekürrens olan 92 hastadan 47'sine tersiyer sitoredüksiyon ve 3 . rekürrens olan 42 hastadan 15 'ine kuaterner sitoredüksiyon cerrahileri uygulandı. Ortanca takip süresi 40 ay olarak tespit edildi (min.: 4 - maks.: 130 ay). Ortalama ve ortanca tanı yaşı sırasıyla $54,1 \pm 11,2$ ve 52,5 yıl idi. Tüm çalışma grubu için ortalama sağ kalım $66,5 \pm 5,1$ ay, ortanca sağ kalım süresi 56 ay olarak tespit edildi. Bir, iki, üç, dört ve beş yıllık sağ kalım oranları sırasıyla \%95,8, \%84;\%68,8, \%55,3 ve $\% 43,4$ olarak bulundu. Histolojik tip, evre, derece ve primer cerrahi prosedür bilgileri Tablo-1'de özetlenmektedir.

Primer operasyon sonrasında $99 \quad(\% 93,3)$ hastaya karboplatin + paklitaksel; 5 (\%4,7) hastaya sisplatin + paklitaksel, $1(0,9 \%)$ hastaya doksorubisin + karboplatin rejimleri uygulanırken, bir hasta cerrahi sonrası kemoterapi almayı kabul etmemiştir. Primer cerrahi sonrası hastalıksız dönem $27(\% 25,4)$ hastada 6 aydan kısa, 32 $(\% 30,2)$ hastada $6-12$ ay arası ve $43(\% 40,6)$ hastada 12 aydan uzun tespit edildi. Dört hastanın hastalıksız dönem bilgisine ulaşılamadı. Hastalıksız dönemi 6 aydan kısa olan hastaların ortalama sağ kalımı $34,9 \pm 4,3$ ay; $6-12$ ay arası olan hastalar için $55,9 \pm 6,3$ ay ve 12 aydan uzun olan hastalar için $65,9 \pm 5,1$ ay olarak tespit edildi $(p:<0,0001)$.

Hasta grubunun tamamının sekonder sitoredüksiyon operasyonları merkezimizde tek jinekolojik onkolog tarafından gerçekleştirildi. İlk rekürrensi tespit edilen vakaların 63'üne hemen sitoredüksiyon kararı verilirken 43 hastaya tek ya da birden fazla kemoterapi sonrası sitoredüksiyon planlandı. Hasta grubunda, ilk rekürrenste $43(\% 40,5)$ hastada tek anatomik alanda rekürrens saptanırken; $57 \quad(\% 53,8)$ hastada birden fazla alanda rekürrens olduğu görüldü. Altı hastanın kayıtlarından hangi 
anatomik alanlarda rekürren kitlesinin olduğu bilgisine net ulaşılamadı. Sekonder sitoredüksiyon sırasında tespit edilen en sık rekürren kitle alanlarının sırasıyla ince barsak yüzeyi, rektosigmoid kolon, vajinal güdük (cuff) ve dalak idi. Sekonder sitoredüksiyon sırasında geride tümör dokusu bırakılmaması hedeflenmiştir. Sekonder, tersiyer ve kuaterner sitoredüktif cerrahilerde uygulanan prosedürler Tablo-2'de açıklanmaktadır.

Tablo-1. Histolojik tip, derece, evre ve primer cerrahi prosedürler.

\begin{tabular}{|c|c|c|}
\hline HISTOLOJIK TIP & Hasta sayısı & $\%$ \\
\hline Seröz papiller & 88 & 83 \\
\hline Endometrioid & 6 & 5,7 \\
\hline Müsinöz & 3 & 2,8 \\
\hline Şeffaf hücreli & 3 & 2,8 \\
\hline Miks & 3 & 2,8 \\
\hline Andiferansiye & 2 & 1,9 \\
\hline ulaşılamadı & 1 & 0,9 \\
\hline \multicolumn{3}{|l|}{ DERECE } \\
\hline 1 & 3 & 2,8 \\
\hline 2 & 7 & 6,6 \\
\hline 3 & 77 & 72,6 \\
\hline 4 & 16 & 15 \\
\hline ulaşılamadı & 3 & 2,8 \\
\hline \multicolumn{3}{|l|}{ EVRE } \\
\hline $1-2$ & 10 & 9,4 \\
\hline $3-4$ & 95 & 89,6 \\
\hline ulaşılamadı & 1 & 0.9 \\
\hline \multicolumn{3}{|l|}{ PRIMMER CERRAHI } \\
\hline TAH+BSO+Omentektomi+BPPLND & 86 & \\
\hline +Apendektomi & 52 & \\
\hline +Splenektomi & 5 & \\
\hline +Kolesistektomi & 6 & \\
\hline +Diyafram stripping & 3 & \\
\hline +Pelvik peritonektomi & 1 & \\
\hline $\begin{array}{l}\text { +Sigmoid kolon rezeksiyonu ve kolostomi } \\
\text { açılması }\end{array}$ & 3 & \\
\hline +Sigmoid kolon rezeksiyonu ve anastomoz & 2 & \\
\hline +Karaciğerden kitle eksizyonu & 1 & \\
\hline +Mide ve pankreastan tümöral kitle eksizyonu & 1 & \\
\hline BSO+Omentektomi+BPPLND & 7 & \\
\hline +Splenektomi & 1 & \\
\hline +lleum rezeksiyonu+ileostomi açılması & 1 & \\
\hline +Apendektomi & 2 & \\
\hline $\begin{array}{l}\text { Vajinal Kaf rezeksiyonu } \\
+ \text { +BSO+Omentektomi+BPPLND }\end{array}$ & 2 & \\
\hline TAH+USO+Omentektomi+BPPLND & 2 & \\
\hline USO+BPPLND+Omentektomi+Apendektomi & 2 & \\
\hline $\mathrm{TAH}+\mathrm{BSO}$ & 6 & \\
\hline +BPPLND & 2 & \\
\hline +Omentektomi & 2 & \\
\hline BSO & 1 & \\
\hline
\end{tabular}

KIsaltmalar: TAH: Total abdominal histerektomi; BSO: bilateral salpingooferektomi; BPPLND: Bilateral pelvik ve paraaortik lenfadenektomi; USO: Unilateral salpingoofreektomi. 
Tablo-2. Sekonder, tersiyer ve kuaterner sitoredüksiyona eklenen prosedürler.

\begin{tabular}{|c|c|}
\hline Sekonder sitordüksiyona eklenen prosedürler & Hasta Sayısı \\
\hline Splenektomi & 15 \\
\hline Omentektomi & 11 \\
\hline BPPLND & 10 \\
\hline Ileum rezeksiyonu+anastomoz & 10 \\
\hline Ileum rezeksiyonu+ileostomi açılması & 9 \\
\hline Rektosigmoid rezeksiyonu+Kolostomi açılması & 6 \\
\hline Rektosigmoid rezeksiyonu+anastomoz & 5 \\
\hline Sağ hemikolektomi+kolostomi açılması & 2 \\
\hline Sağ hemikolektomi+anastomoz & 1 \\
\hline Apendektomi & 4 \\
\hline Umblikal herni onarımı & 4 \\
\hline Kolesistektomi & 3 \\
\hline Diyafram stripping & 2 \\
\hline Karaciğerden tümör kitlesi eksizyonu & 1 \\
\hline Karaciğer argon koterizasyonu & 1 \\
\hline Pankreastan tümör kitlesi çıkarılması & 1 \\
\hline Pelvik peritonektomi & 1 \\
\hline Sol USO & 1 \\
\hline Rektovajinal fistül onarımı & 1 \\
\hline \multicolumn{2}{|l|}{ Tersiyer sitoredüksiyona eklenen prosedürler } \\
\hline Rektosigmoid kolon reseksiyonu+kolostomi açılması & 9 \\
\hline Rektosigmoid kolon rezeksiyonu+anastomoz & 1 \\
\hline Splenektomi & 6 \\
\hline İleum rezeksiyonu+ileostomi açılması & 4 \\
\hline İleum rezeksiyonu+anastomoz & 3 \\
\hline Barsak perforasyon onarımı ve Bogatobag uygulaması & 2 \\
\hline İnguinal lenf nodu diseksiyonu & 2 \\
\hline Diyaframdan tümör eksizyonu & 1 \\
\hline \multicolumn{2}{|l|}{ Kuaterner sitoredüksiyona eklenen prosedürler } \\
\hline Laparotomi ile tümör kitlesi eksizyonu & 5 \\
\hline Vajinal kaftan tümör kitlesi eksizyonu & 3 \\
\hline Rektosigmoid kolon rezeksiyonu+kolostomi açılması & 3 \\
\hline Rektosigmoid kolon rezeksiyonu+kolostomi açılması+splenektomi & 1 \\
\hline İleum rezeksiyonu +ileostomi açılması & 1 \\
\hline Barsak perforasyon onarımı+Bogatobag uygulaması & 1 \\
\hline Vezikovajinal fistül onarımı & 1 \\
\hline
\end{tabular}


İkinci rekürrens gelişen 47 hastaya tersiyer sitoredüksiyon operasyonu gerçekleştirildi. $\mathrm{Bu}$ vakalara bakıldığında; 36 hastada tek alanda, 11 hastada birden fazla anatomik alanda rekürren kitle olduğu görüldü. Tümör kitlelerinin en sık görüldüğü anatomik alanlar sırasıyla ileum, jejunum, rektosigmoid kolon ve vajina güdüğü idi.

Tersiyer sitoredüksiyon yapılan hastaların ortalama sağ kalımı $73,8 \pm 7,3$ ay iken, tersiyer sitoredüksiyon yapılmayan grubun sağ kalımı $52,0 \pm 5,6$ ay idi (p:0,039) (Şekil-1). Tersiyer sitoredüksiyon kararı verilen hastaların hastalıksız döneme göre dağılımlarına bakıldığında; 6 aydan kısa hastalıksız dönemi olan hastaların \%44,4'üne, 6-12 ay arası olanların \%46,9 'una ve 12 aydan uzun hastalıksız dönemi olan hastaların \%44,2'sine tersiyer sitoredüksiyon yapıldığı görüldü $(p:<0,05)$. Tersiyer sitoredüksiyon yapılan 47 hastadan 35 ' $\mathrm{i}$ platin duyarlı, 12'si ise platin dirençli idi. Bu grupta platin dirençli hastaların ortalama sağ kalımı $44,4 \pm 6,4$ ay iken platin duyarlı hastaların ortalama sağ kalımı $78,8 \pm 8,2$ ay olarak tespit edildi ( $p: 0,121)$ (Şekil-2).

Tersiyer sitoredüksiyon hastalarında; tek alan rekürrensi olanların sağ kalımı 59,0 $\pm 6,4$ ay iken, birden fazla alanda rekürrensi olanlarda sağ kalım $48,0 \pm 9,1$ ay olarak hesaplandı ( $p:>0,05$ ).

Kırk yedi hastanın takibinde 15 hastada üçüncü kez rekürrens nedeniyle kuarterner sitoredüksiyon operasyonu yapıldı. $\mathrm{Bu} 15$ hastadan 9 (\%60)'unda tek anatomik alanda rekürrens saptanırken, 6 (\%40) hastada birden fazla alanda rekürrens tespit edildi.

Dördüncü kez opere edilen 15 hastanın ortalama sağ kalımı $63,7 \pm 7,5$ ay iken, opere edilmeyen hastalarda sağ kalım $62,7 \pm 8,3$ ay olarak bulundu (p:0,616) (Şekil-3).

Kuarterner sitoredüksiyon yapılan 15 hastanın 2 'si $(\% 13,3)$ platin dirençli iken, $13(\% 86,7)$ 'ünün platin duyarlı idi. Platin dirençli hastaların ortalama sağ kalım süresi $50,5 \pm 10,2$ ay, platin duyarlı hastaların ise $63,2 \pm 8,0$ ay olarak bulundu (p:0,987) (Şekil-4).

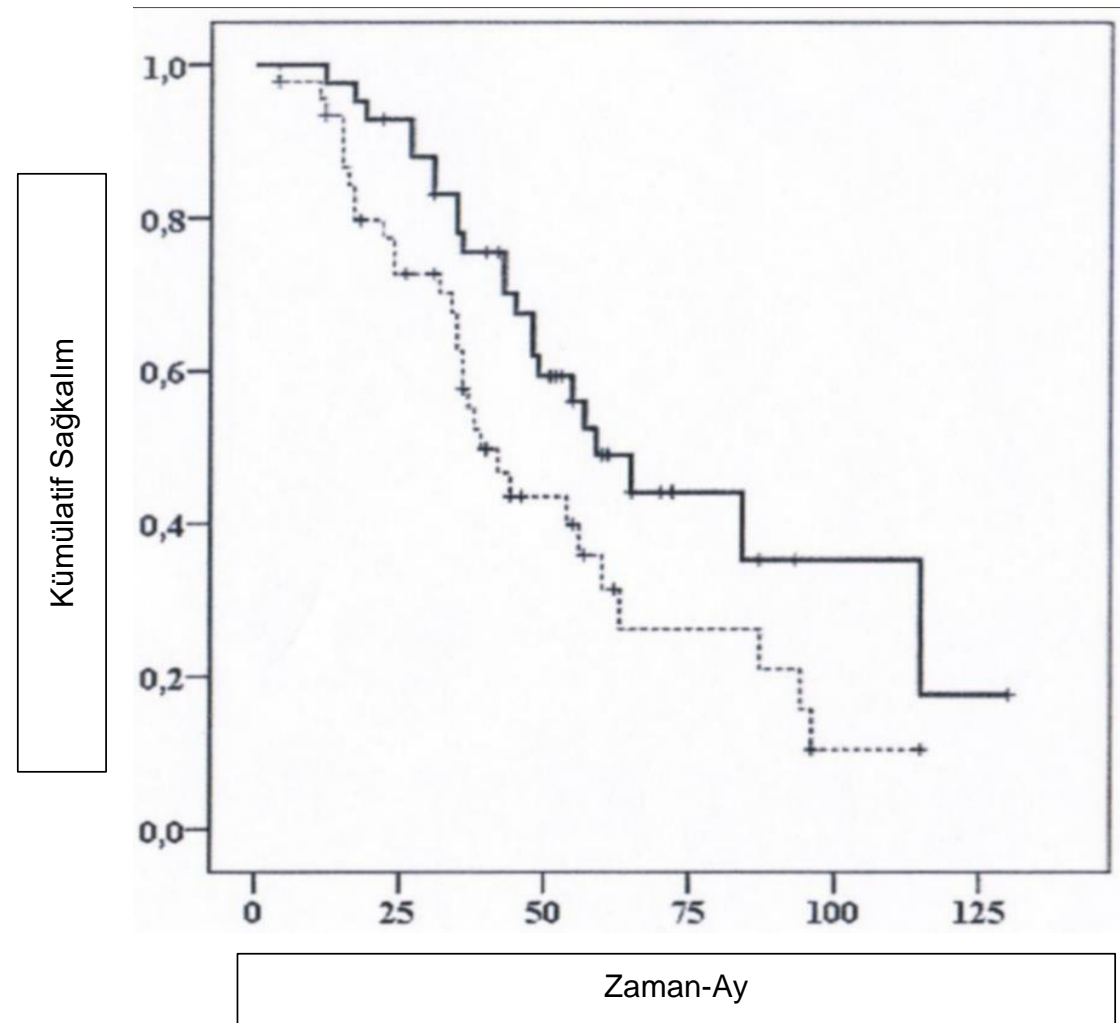

$$
\begin{aligned}
& \text { Tersiyer } \\
& \text { sitoredüksiyon (+) } \\
& \text { …... Tersiyer } \\
& \text { sitoredüksiyon (-) }
\end{aligned}
$$

Şekil-1. İkinci rekürrensi olan, tersiyer sitoredüksiyon yapılan ve yapılmayan hastaların ortalama sağ kalım süreleri. 


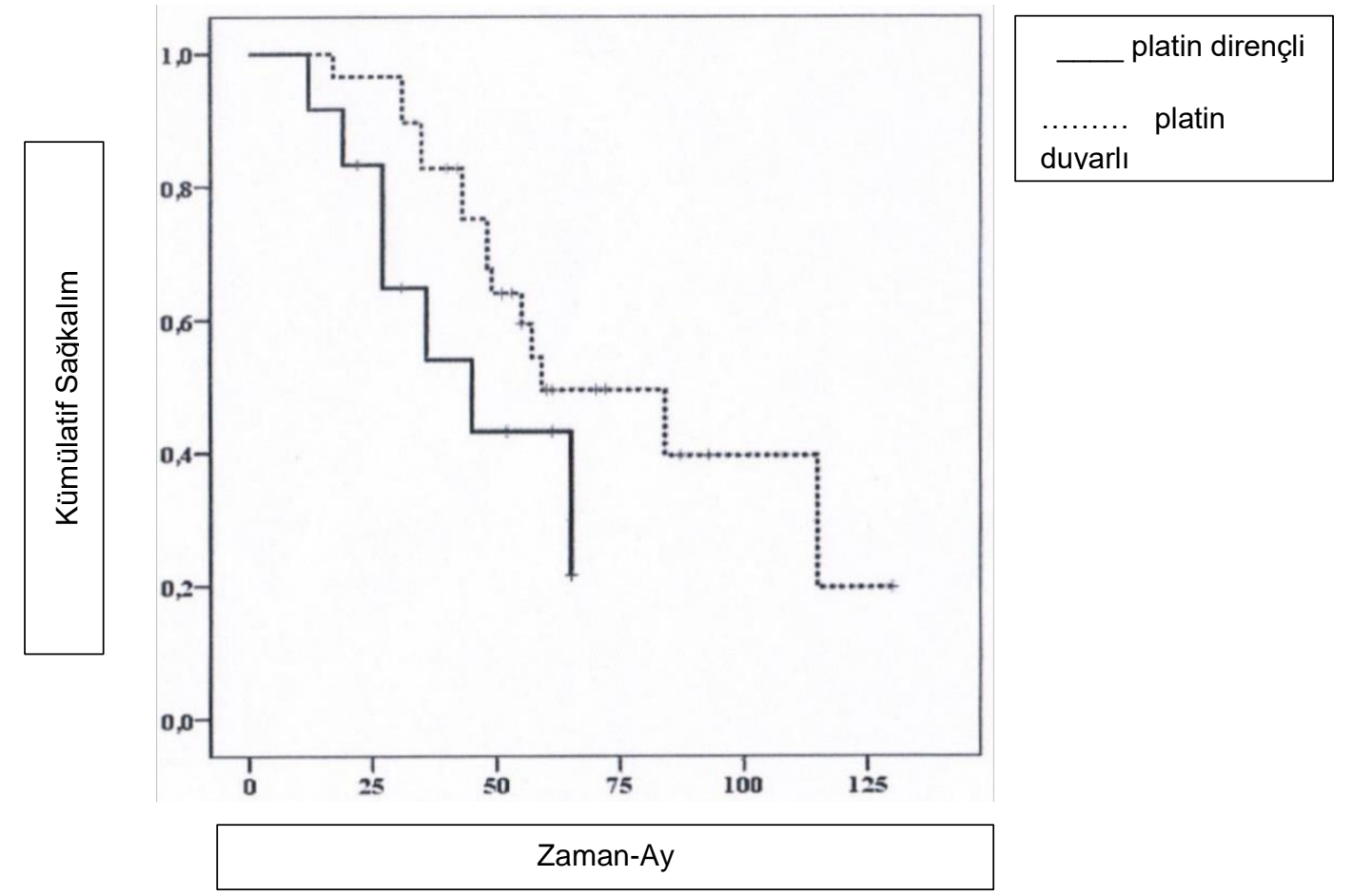

Şekil-2. Tersiyer sitoredüksiyon yapılan platin duyarlı ve dirençli hastaların ortalama sağ kalım süreleri.

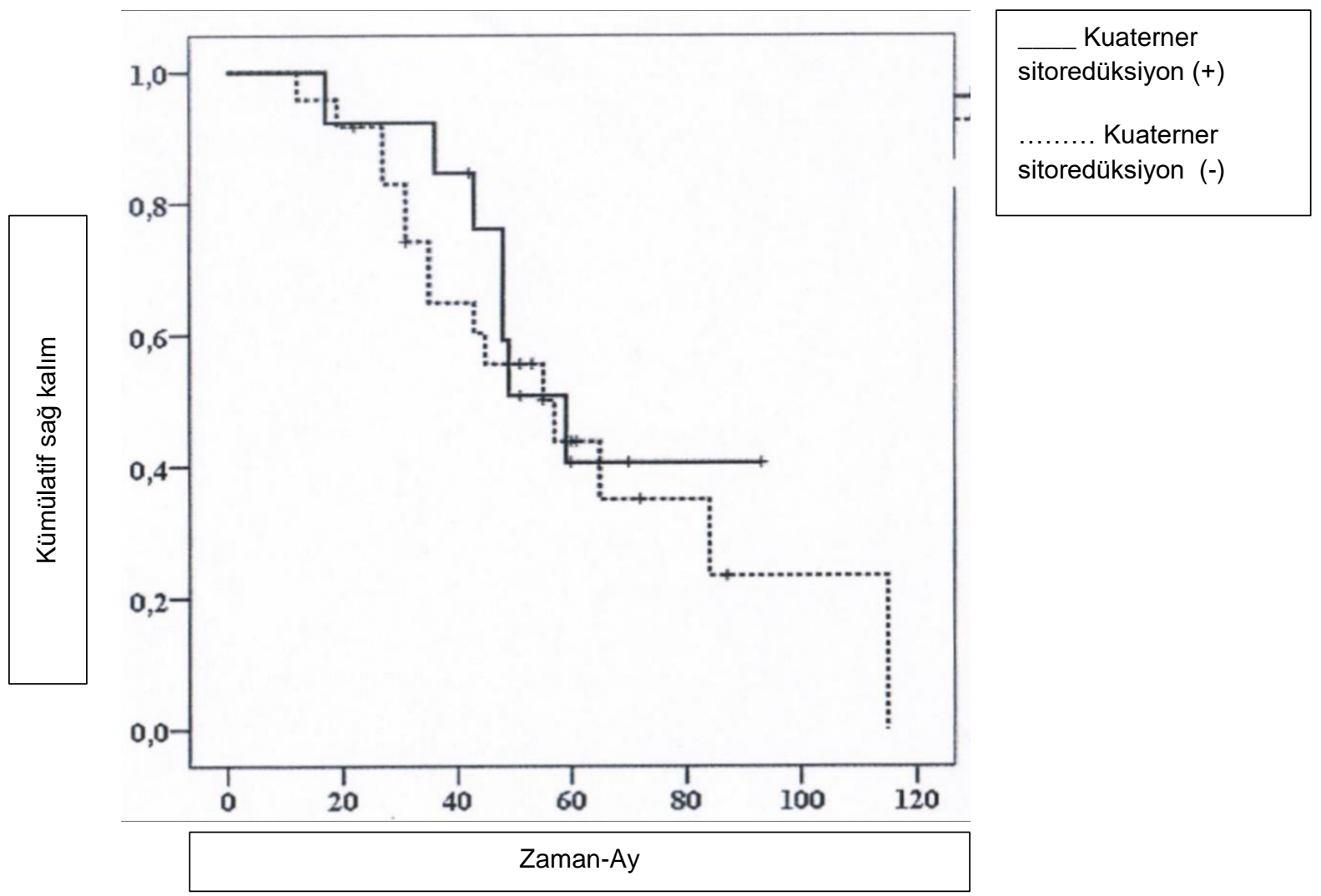

Şekil-3. Üçüncü rekürrensi olan, kuaterner sitoredüksiyon yapılan ve yapılmayan hastaların sağ kalım süreleri. 


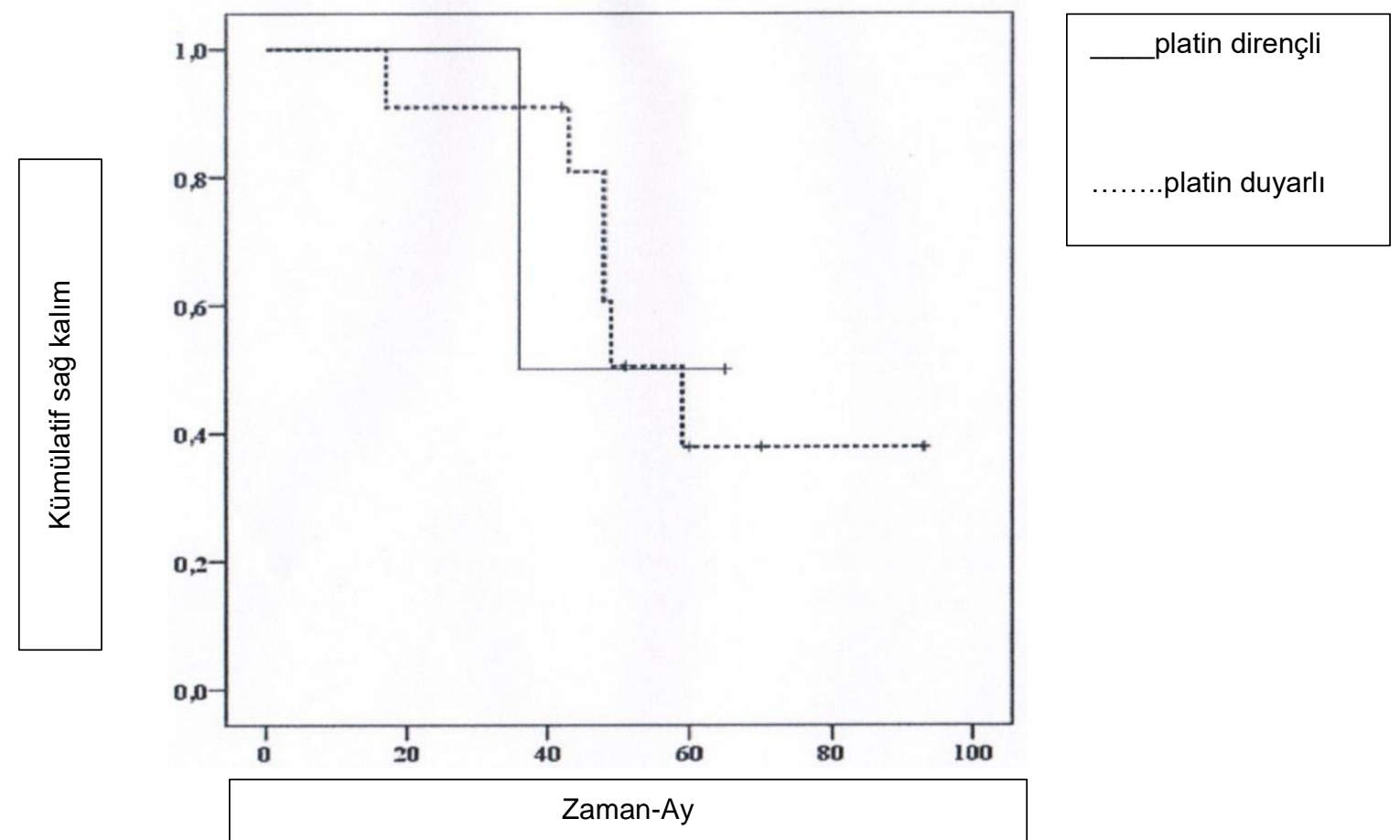

Şekil-4. Kuaterner sitoredüksiyon yapılan platin duyarlı ve dirençli hastaların sağ kalım süreleri.

Tablo-3. Sitoredüktif cerrahiler sırasında oluşan intraoperatif komplikasyonlar.

\begin{tabular}{|c|c|c|c|c|c|}
\hline $\begin{array}{l}\text { İntraoperatif } \\
\text { komplikasyon } \\
\text { tipleri }\end{array}$ & $\begin{array}{l}\text { Primer } \\
\text { Sitoredüksiyon }\end{array}$ & $\begin{array}{l}\text { Sekonder } \\
\text { Sitoredüksiyon }\end{array}$ & $\begin{array}{l}\text { Tersiyer } \\
\text { Sitoredüksiyon }\end{array}$ & $\begin{array}{l}\text { Kuarterner } \\
\text { Sitoredüksiyon }\end{array}$ & ' $P$ ' değeri \\
\hline $\begin{array}{l}\text { Barsak serozal } \\
\text { defekt oluşumu }\end{array}$ & $4(\% 3,7)$ & $9(\% 8)$ & $2(\% 4,3)$ & - & \\
\hline $\begin{array}{l}\text { Barsak tam kat } \\
\text { defekt oluşumu }\end{array}$ & $1(\% 0,9)$ & $5(\% 4,7)$ & $4(\% 8,5)$ & - & \\
\hline $\begin{array}{l}\text { Mesane duvarı tam } \\
\text { kat defekt oluşumu }\end{array}$ & $3(\% 2,8)$ & $1(\% 0,9)$ & - & $1(\% 6,6)$ & \\
\hline $\begin{array}{l}\text { Majör damar } \\
\text { yaralanması }\end{array}$ & $1(\% 0,9)$ & $2(\% 1,8)$ & - & - & \\
\hline Ureter yaralanması & - & $3(\% 2,8)$ & - & - & \\
\hline $\begin{array}{l}\text { Diyafram } \\
\text { perforasyonu }\end{array}$ & - & $1(\% 0,9)$ & - & - & \\
\hline $\begin{array}{l}\text { Mesane ve barsak } \\
\text { yaralanması }\end{array}$ & - & - & $1(\% 2,1)$ & - & \\
\hline $\begin{array}{l}\text { Üreter ve majör } \\
\text { damar yaralanması }\end{array}$ & - & - & - & $1(\% 6,6)$ & \\
\hline TOPLAM & $9(\% 8,4)$ & $20(\% 18,8)$ & $7(\% 14,8)$ & $2(\% 13,3)$ & ,184 \\
\hline
\end{tabular}


Tablo-4. Sitoredüktif cerrahiler sonrasında gelişen postoperatif komplikasyon dereceleri.

\begin{tabular}{llllll}
\hline $\begin{array}{l}\text { Postoperatif } \\
\text { komplikasyon } \\
\text { derecesi }\end{array}$ & $\begin{array}{l}\text { Primer } \\
\text { Sitoredüksiyon }\end{array}$ & $\begin{array}{l}\text { Sekonder } \\
\text { Sitoredüksiyon }\end{array}$ & $\begin{array}{l}\text { Tersiyer } \\
\text { Sitoredüksiyon }\end{array}$ & $\begin{array}{l}\text { Kuarterner } \\
\text { Sitoredüksiyon }\end{array}$ & $\begin{array}{l}\mathbf{P} \\
\text { değeri }\end{array}$ \\
\hline Derece 1 & 2 & 8 & 3 & - \\
Derece 2 & 6 & 5 & - & - \\
Derece 3 & 7 & 5 & 4 & 3 \\
Derece 4 & - & - & 4 & - \\
Derece 5 & - & - & 1 & - & \\
TOPLAM & $15(\% 14,1)$ & $18(\% 16,9)$ & $12(\% 25,5)$ & $3(\% 20)$ & 0,390 \\
\hline
\end{tabular}

Tablo-5. Postoperatif dönemde yoğun bakım ihtiyacı.

\begin{tabular}{llllll}
\hline & $\begin{array}{l}\text { Primer } \\
\text { Sitoredüksiyon }\end{array}$ & $\begin{array}{l}\text { Sekonder } \\
\text { Sitoredüksiyon }\end{array}$ & $\begin{array}{l}\text { Tersiyer } \\
\text { Sitoredüksiyon }\end{array}$ & $\begin{array}{l}\text { Kuarterner } \\
\text { Sitoredüksiyon }\end{array}$ & P değeri \\
\hline $\begin{array}{l}\text { Yoğun bakım } \\
\text { ihtiyacı (+) }\end{array}$ & $6(\% 5,7)$ & $6(\% 5,7)$ & $11(\% 23,4)$ & $5(\% 33,3)$ & $<, 0001$ \\
$\begin{array}{l}\text { Yoğun bakım } \\
\text { ihtiyacı ( - ) }\end{array}$ & $100(\% 94,3)$ & $100(\% 94,3)$ & $36(\% 76,4)$ & $10(\% 66,6)$ & \\
\hline
\end{tabular}

Primer, sekonder, tersiyer ve kuarterner sitoredüksiyon operasyonlarının intraoperatif ve postoperatif komplikasyonları sırasıyla Tablo-3 ve Tablo-4'te özetlenmektedir.

Hastaların postoperatif dönemde yoğun bakım intiyacı Tablo-5'de özetlenmiştir. Operasyon sonrası yoğun bakım intiyacı oranları tersiyer ve kuaterner sitoredüksiyonlar sonrasında anlamlı olarak yüksek bulundu ( $p:<0,0001)$.

\section{TARTIŞMA}

Rekürren over kanseri vakalarının yönetiminde cerrahinin yeri konusunda kesin bir fikir birliği bulunmamaktadır. Hastalığın tabiatı nedeniyle konu ile ilgili çalışmalar genellikle retrospektif hasta analizlerinden oluşmaktadır. Literatürdeki çalışmalarda genel olarak sekonder, tersiyer hatta kuarterner cerrahilerin uygun hastalarda uygulanması halinde sağ kalıma olumlu etkisi olacağı görüşü hakimdir. Bu konu ile ilgili güncel prospektif randomize bir çalışma jinekolojik onkoloji grubu tarafından gerçekleştirilmiş ve platin duyarlı over kanseri hastalarında sekonder sitoredüktif cerrahinin, sadece kemoterapiye sağ kalım anlamında benzer olduğu görüşü bildirilmiştir (14). Tersiyer ve kuaterner sitoredüksiyon sonuçları ile ilgili retrospektif çalışmalar mevcuttur.
Arvas ve ark.'nın çok merkezli retrospektif çalışmasında tersiyer sitoredüksiyonun sağ kalımı uzattığı belirtilmiştir. Bu çalışmada optimal tersiyer sitoredüksiyonu öngören parametrelerin ilk ve ikinci sitoredüktif cerrahilerin optimal oluşu, tedavisiz dönemin uzunluğu, ikinci sitoredüksiyon ve relaps arasındaki süre, rekürren kitle boyutunun olduğu bildirilmiştir (17). Fotopolu ve ark. geride kalan tümörün tersiyer sitoredüktif cerrahinin sağ kalıma etkisini belirleyen en önemli belirleyici faktör olduğu sonucuna ulaşmışlardır (19). Falcone ve ark.'nın çok merkezli çalışması da tersiyer sitoredüksiyon yapılan hastalarda, geride tümör kalmayanların, kalanlara göre anlamlı olarak daha uzun sağ kalımının olduğunu göstermişlerdir (21). Leitaou ve ark.'nın 26 hastanın sonuçlarını inceleyen çalışması da tersiyer sitoredüktif cerrahinin sağ kalımı uzatacağını, ancak bu etkinin tedavisiz dönemi uzun olan ve cerrahisi optimal olan hastalarda belirgin olduğunu bulmuşlardır (16). Japonya'dan yapılan çok merkezli retrospektif bir çalışmanın sonucu da tersiyer sitoredüksiyonun sağ kalımı uzatacağı yönündedir (22). Bizim çalışmamızda ikinci rekürens sonrası cerrahi yapılmayan hastaların ortalama sağ kalımı, tersiyer sitoredüksiyon yapılan hastalara oranla daha kısa bulunmuştur. Bu sonuç literatürdeki diğer çalışmaları desteklemektedir. Tersiyer 
sitoredüktif cerrahi yapılan hastalar içerisinde platin duyarlı olan ve tek anatomik alanda rekürrensi olanların sağ kalımının daha uzun olması yine literatürdeki benzer çalışma sonuçları ile örtüşmektedir (21). Yakın zamanda yayınlanan bir çalışmada rekürren over kanseri vakalarının, tersiyer cerrahilerinde optimal sitoredüksiyonu sağlamak amacıyla yapılan geniş üst abdominal cerrahi prosedürlerin güvenli olduğu belirtilmiştir (23). Bu vaka serisinde de tersiyer sitoredüktif cerrahilerde splenektomi, barsak rezeksiyonu, barsak anastomozu ve diyafram striping gibi ek prosedürler uygulanmıştır.

Fotopolou ve ark. 2013 yılında 49 rekürren over kanseri vakasında kuarterner sitoredüktif cerrahinin etkisini araştırmışlardır. Çalışmalarının sonucunda kuarterner sitoredüksiyon ile geride tümör dokusu bırakılmayan hastaların ortalama sağ kalımı, geride tümör kalanlardan belirgin daha uzun bulunmuştur. Aynı çalışma kuarterner sitoredüksiyon sonrası kemoterapi alan hastaların almayanlara göre sağ kalımını anlamlı olarak daha uzun bulmuş ve ileri evre rekürren vakalarda bile geride tümör dokusu bırakmamak üzere maksimum cerrahi efor sarf edilmesi gerektiğini belirtmişlerdir (20). Toplam 15 hastanın sonuçlarını inceleyen, Shih ve ark. da kuarterner sitoredüksiyon için sağ kalıma olumlu katkısı olabileceğini bu katkının özellikle geride tümör dokusu bırakılmayan, optimal sitoredüktif cerrahi yapılabilen hastalarda olacağı yorumunu yapmışlardır (18). Fanfani ve ark. da tersiyer sitoredüksiyon yapılan ve sonrasında rekürrens gelişen 18 hastanın 12'sine kuarterner sitoredüksiyon yapıldığı hasta sonuçlarına baktığında, kuarterner sitoredüksiyon yapılan grubun sağ kalımını, yalnızca kemoterapi alanlara göre daha uzun bulmuştur. Özellikle tedavisiz dönemi uzun olan hastalarda bu etkinin belirgin olduğunu belirtirken, geride bırakılan tümör dokusunun sağ kalım üzerine anlamlı etkisi olmadığını belirtmişlerdir (15). Bu çalışmada ise kuarterner sitoredüksiyon yapılan 15 hasta ile yapılmayıp medikal tedavi verilen 27 hastada sağ kalım benzer bulundu ve kuarterner sitoredüksiyonun sağ kalıma olumlu etkisi gösterilemedi. Hasta sayısının sınırlı olmasının bu sonuca neden olduğu düşünülebilir. Kuarterner sitoredüksiyon yapılan grupta platin duyarlı hastaların sağ kalımı, dirençli olanlara göre daha uzun bulundu. Ancak yine hasta sayısının az oluşu istatistiksel anlama ulaşmayı engellemiş olabilir.
Literatürde tersiyer sitoredüktif cerrahinin, perioperatif komplikasyon oranları \%15-30 civarında bildirilmektedir $(22,23)$. Bu çalışmada ise tersiyer sitoredüktif cerrahinin intraoperatif ve postoperatif komplikasyon oranları sırasıyla $\% 14,8$ ve \%25 idi. Postoperatif 4 hastada derece 4, 1 hastada ise derece 5 morbidite yani postoperatif ilk 24 saat içerisinde ölüm izlenmiş olması önemli idi. Bu oranların literatür ile uyumlu olduğu düşünülmektedir. Kuarterner sitoredüksiyonun intaoperatif komplikasyon oranları da \%15-28 arasında değişmektedir (18, $20,26)$. Yine bu çalışmanın kuarterner sitoredüksiyon için intra ve postoperatif komplikasyonları sırasıyla \%13,3 ve \%20 saptandı. Bu sonuçların da literatür ile uyumlu olduğu görülmektedir.

Postoperatif yoğun bakım ihtiyacının geçirilen tersiyer ve kuarterner sitoredüktif cerrahiler sonrası anlamlı olarak artması çalışmanın önemli sonuçlarından biridir. Bu açıdan bakıldığında geniş ve özellikli cerrahi operasyonlar olan tersiyer ve kuarterner sitoredüksiyonların, postoperatif bakımın uygun şekilde sağlanabileceği, yoğun bakım intiyacının karşılanabileceği merkezlerde gerçekleştirilmesi gerektiği açıktır.

$\mathrm{Bu}$ çalışmanın başlıca kısıtıııkları retrospektif çalışmaların genel özelliklerini taşıyor olması, hasta sayısının sınırlı olmasıdır. Gerçekleştirilen operasyonlar sonrası geride kalan tümör yükünün boyut olarak objektif gösterilememesi yine önemli kısıtlayıcı faktörlerden biri olup, geride kalan tümör boyutunun sağ kalıma etkisi konusunda yorum yapmamızı engellemektedir.

\section{SONUÇ}

Güncel çalışmalarda sekonder sitoredüksiyonun sağ kalım açısından sadece kemoterapi verilen hastalara üstün olmadığı belirtilmektedir. $\mathrm{Bu}$ bağlamda düşünüldüğünde tersiyer ve kuaterner sitoredüktif cerrahilerin sağ kalım yararını inceleyen ve morbidite, mortalitesini değerlendiren prospektif randomize çalışmalara intiyaç olduğu görülmektedir. Retrospektif çalışmaların analizleri bu noktada dikkatle değerlendirilmelidir. Her ne kadar bu çalışmada da olduğu gibi tersiyer sitoredüksiyonun sağ kalıma olumlu etkisi retrospektif çalışmalarda gösterilmiş olsa da özellikle hangi hasta grubunun esas sağ kalım faydasını göreceği kesin değildir ve çelişkiler mevcuttur. Platin duyarlı, sınırlı rekürrens kitlesi olan grupta sağ 
kalımın daha uzun olabileceği sonucuna bu çalışmada ulaşılmıştır. Literatürde de özellikle geride tümörün bırakılmadığı, tedavisiz dönemi uzun olan ve rekürrens kitlesi yaygın olmayan hasta grubunda sağ kalımın daha uzun olacağı görüşü hakimdir. Ancak belirtildiği gibi bu parametrelerin net etkisini ortaya koyacak randomize çalışmalar gerekmektedir. Kuarterner sitoredüksiyon için de benzer yorumlar geçerlidir. $\mathrm{Bu}$ ileri cerrahilerin perioperatif komplikasyon oranları ve her cerrahi ile artan yoğun bakım intiyacı göz önünde bulundurulduğunda bu cerrahilerin konunun uzmanı cerrahlar tarafından ve uygun imkanlara sahip merkezlerde yapılması gerekliliği açıktır.

\section{Çıkar çatışması}

Yazarlar arasında çıkar çatışması bulunmamaktadır.

\section{Kaynaklar}

1. Bristow RE. Surgical standards in the management of ovarian cancer. Curr Opin Oncol Sep 2000; 12 (5): 474-80.

2. Chi DS, Franklin CC, Levine DA et al. Improved optimal cytoreduction rates for stages IIIC and IV epithelial ovarian, fallopian tube and primary peritoneal cancer: a change in surgical approach. Women's Oncol Rev 2004; 4, (4): 263-4.

3. du Bois A, Reuss A, Pujade-Lauraine E, Harter P, Ray-Coquard I, and Pfisterer J. Role of surgical outcome as prognostic factor in advanced epithelial ovarian cancer: A combined exploratory analysis of 3 prospectively randomized phase 3 multicenter trials. Cancer 2009; 115 (6): 1234-44.

4. Kapp KS,Kapp DS, Poschauko $\mathrm{J}$ et al. The prognostic significance of peritoneal seeding and size of postsurgical residual in patients with stage III epithelial ovarian cancer treated with surgery, chemotherapy, and high-dose radiotherapy. Gynecol Oncol 1999; 74 (3): 400-7.

5. Harter $P$, Muallem ZM, Buhrmann $C$ et al. Impact of a structured quality management program on surgical outcome in primary advanced ovarian cancer. Gynecol Oncol 2011;121 (3): 615-9.

6. Muggia FM, Braly PS, Brady MF et al. Phase III randomized study of cisplatin versus paclitaxel versus cisplatin and paclitaxel in patients with suboptimal stage III or IV ovarian cancer: A Gynecologic Oncology Group study. J Clin Oncol 2000; 18 (1): 106-15.

7. Zang RY, Zhang ZY, Li ZT et al. Impact of secondary cytoreductive surgery on survival of patients with advanced epithelial ovarian cancer. Eur J Surg Oncol 2000, 26 (8): 798-804.

8. Zang RY, Li ZT, Tang J et al. Secondary Cytoreductive Surgery for Patients with Relapsed Epithelial Ovarian Carcinoma: Who Benefits? Cancer 2004; 100 (6): 1152-61.

9. Ayhan A,Gultekin M, Taskiran C et al. The role of secondary cytoreduction in the treatment of ovarian cancer: Hacettepe University experience. Am J Obstet Gynecol 2006; 194 (1): 49-56.

10. Bristow RE, Puri I and Chi DS. Cytoreductive surgery for recurrent ovarian cancer: A meta-analysis. Gynecol Oncol 2009; 112 (1): 265-74.

11. Onda T, Yoshikawa H, Yasugi T, Yamada M, Matsumoto K, and Taketani Y. Secondary cytoreductive surgery for recurrent epithelial ovarian carcinoma: Proposal for patients selection. Br J Cancer 2005; 92 (6): 1026-32.

12. Chi DS, McCaughty K, Diaz JP et al. Guidelines and selection criteria for secondary cytoreductive surgery in patients with recurrent, platinum-sensitive epithelial ovarian carcinoma. Cancer 2006; 106 (9): 1933-9.

13. Bickell NA, Egorova N, Prasad-Hayes $M$ et al. Secondary Surgery Versus Chemotherapy for Recurrent Ovarian Cancer. Am J Clin Oncol Cancer Clin Trials 2018; 41 (5): 458-64.

14. Coleman RL, Spirtos NM, Enserro $D$ et al. Secondary surgical cytoreduction for recurrent ovarian cancer. $N$ Engl J Med 2019; 381 (20): 1929-39.

15. Fanfani F, Fagotti A, Ercoli A et al. Is There a Role for Tertiary (TCR) and Quaternary (QCR) Cytoreduction in Recurrent Ovarian Cancer? Anticancer Res 2015; 35 (12): 6951-5.

16. Leitao Jr MM, Kardos S, Barakat RR, and Chi DS. Tertiary cytoreduction in patients with recurrent ovarian carcinoma. Gynecol Oncol 2004; 95 (1): 181-8.

17. Arvas M, Salihoglu $Y$, Sal $V$ et al. Tertiary cytoreduction for recurrent epithelial ovarian cancer: A multicenter study in Turkey. Asian Pacific J Cancer Prev 2016; 17 (4): 1909-15.

18. Shih KK, Chi DS, Barakat RR, and Leitao Jr MM. Beyond Tertiary Cytoreduction in Patients With Recurrent Epithelial Ovarian, Fallopian Tube, or Primary Peritoneal Cancer. Gynecol Oncol 2010, 116 (3): 364-9. 
19. Fotopoulou C, Zang R, Gultekin M et al. Value of tertiary cytoreductive surgery in epithelial ovarian cancer: An international multicenter evaluation. Annals of Surgical Oncology 2013; 20 (4): 1348-54.

20. Fotopoulou C,Savvatis K,Kosian P et al. Quaternary cytoreductive surgery in ovarian cancer: Does surgical effort still matter. Br J Cancer 2013; 108 (1): 32-8.

21. Falcone $F$, Scambia $C$, Benedetti Panici $P$ et al. Tertiary cytoreductive surgery in recurrent epithelial ovarian cancer: A multicentre MITO retrospective study. Gynecol Oncol 2017; 147 (1): 66-72.

22. Hirakawa $T$, Minaguchi $T$, Itani $Y$ et al. Current status of tertiary debulking surgery and prognosis after secondary debulking surgery for recurrent müllerian epithelial cancer in Japan: a retrospective analysis of 164 patients (KCOG-G1402). World Journal of Surgical Oncology 2017; 15 (132): 1-7

23. Bacalbasa N, Balescu I, Vilcu M, Dima $S$ and Brezean I. Upper abdominal resection as part of tertiary cytoreduction for relapsed ovarian cancer. In Vivo 2020; 34 (1): 407-11

24. Dogan NU, Schneider A, Chiantera V, Dogan S, and Dursun P. Tertiary cytoreduction in the setting of recurrent ovarian cancer (Review). Oncol Lett 2013; 6 (3): 642-7.

25. Karam AK, Santillan A, Bristow RE et al. Tertiary cytoreductive surgery in recurrent ovarian cancer: Selection criteria and survival outcome. Gynecol Oncol 2007; 104 (2): 377-80.

26. Bacalbasa N, Balescu I, Dima S,Brasoveanu V,Popescu I. The role of quaternary cytoreduction in recurrent epithelial ovarian cancer: a single center experience. Anticancer Res 2015; 35 (6): 3519-23. 